\title{
Repair of hypospadias in Mosul Paediatric Surgery Centre
}

\author{
(analysis of 125 cases)
}

Abdulrahman A. Sulaiman

Department of Surgery, College of Medicine, University of Mosul.

(Ann. Coll. Med. Mosul 2008; 34(2): 109-117).

Received: $2^{\text {nd }}$ Mar 2008; Accepted: $24^{\text {th }}$ Sept 2008.

\begin{abstract}
Aim: A retrospective study of 125 cases with different types of hypospadias. Evaluation of the surgical procedure for each type to choose the suitable techniques for each problem.

Patients \& methods: 125 cases of hypospadias were admitted and treated at Al-Khansa'a Paediatric Surgery centre in Mosul during the Period from Jan. 2005 to Feb. 2007. Their age ranged between 6 months to 12 years. All types of Hypospadias were managed using different techniques. Majority of them were distal type. The surgical repair varies according to the type of hypospadias. Catheters were used for different periods according to the procedure used. Hospitalization period also varied according to the severity and techniques used.
\end{abstract}

Results: The types of hypospadias varied from glanular to penoscrotal. Glanular were 14 patients, coronal and sub coronal were 48 patients, distal penile were 37 , mid shafts were 18 patients, proximal and peno-scrotal type were 8 patients. The types of repair used were, MAGPI in 41 patients $(33,6 \%)$, TIP technique in 75 patients $(60 \%)$, Mathiew technique in 4 patients $(3,2 \%)$, and Onlay tube flab in 5 patients $(4 \%)$. Associated problems found with hypospadias repair were; Circumcision in ten patients (six coronal, three subcoronal and distal hypospadias, and only one case with proximal hypospadias). Chordee found in eight patients. Torsion of the shaft of penis in 5 patients (four with mild degree and only one with severe degree). Major complications such as stenosis in 18 patients, fistula in 16 patients and flap or skin necrosis in 3 patients.

Conclusions: There is no single procedure which could be used for all types of hypospadias, but the TIP techniques can be used for a wide range of hypospadias from coronal up to penoscrotal type and this techniques is simple, quick, single stage procedure, and it offers good functional and cosmetic results. The presence of circumcision prior to the repair is not a problem in repairing distal hypospadias but it could be a problem in the proximal type.

Key words: Hypospadias; Repair of hypospodias.

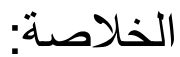

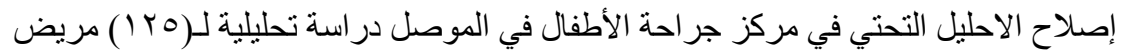

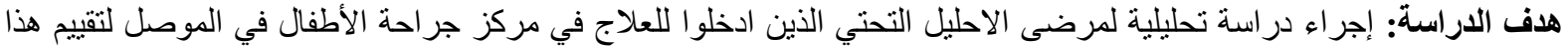

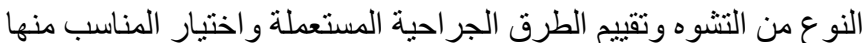

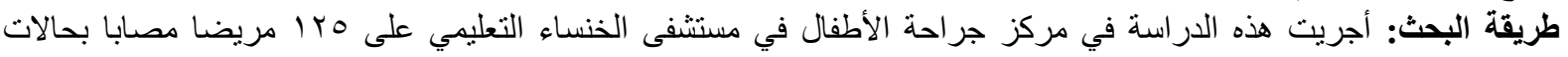

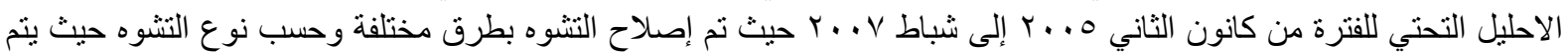

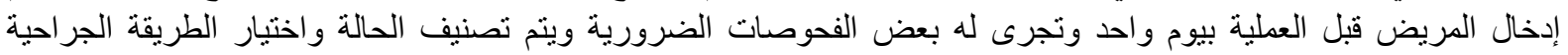

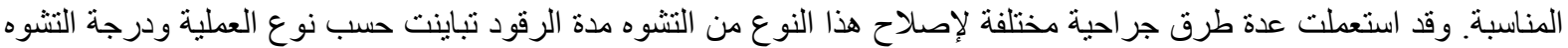

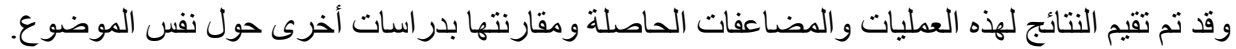

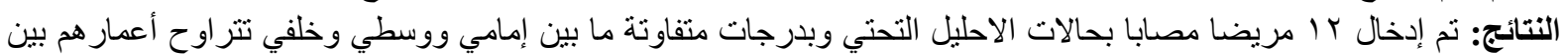

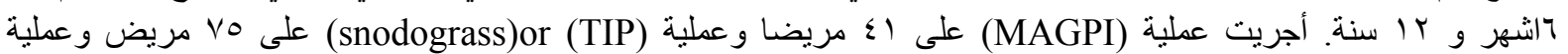


على أربع مرضى فقط وخمس عمليات (Onlay flap tube) على حالات تشوه شديدة. وكان هنالك حالات (MATHIEW)

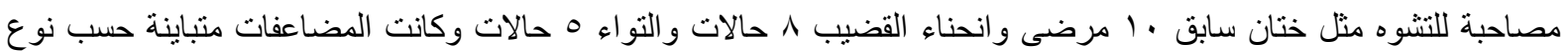

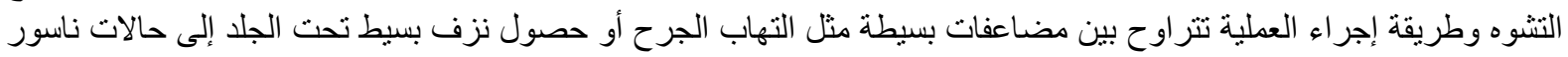

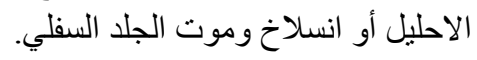

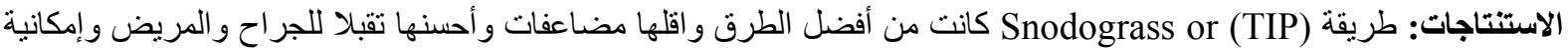

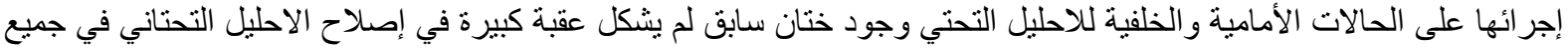

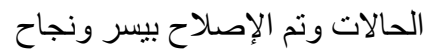
مفتاح البحث: المبال التحتاني، علاج الاحليل التحتي.

$\mathrm{H}$ ypospadias is a common congenital anomaly with an incidence of 1 per 125 to 300 live male births ${ }^{(1)}$. The causes of hypospadias are essentially unknown although several suggestions were put. Some endocrine disorders have been described, mainly caused by insufficient secretion of androgens or insufficient response by the target tissue. However, in very few cases these disorders can be detected ${ }^{(2-4)}$. Some genetic disorder ${ }^{(5)}$ could explain why hypospadias can be found in several members of the same family. Young and old mothers are more prone to carry a baby with hypospadias. Baby with low birth weight ${ }^{(6)}$ and twins also have higher risk of having hypospadias, possibly explained by placental insufficiency ${ }^{(7)}$. The significant increase in hypospadias over the last 20 years, raise the role of possible environmental factors ${ }^{(9,10)}$ e.g. hormonal disruption and pesticides ....etc.

The hypospadiac penis presented with a urethral orifice proximal to the usual site ${ }^{(10)}$. The urethral orifice may terminate just proximal to the glans (glanular hypospadias), at some point along the penile shaft (penile hypospadias) at the anterior margin of the scrotum (penoscrotal hypospadias), or in the perineum with bifid scrotum (perineal hypospadias). Hypospadias may be associated with ventral curvature of penis called chordee, which is accentuated by erection $^{(11)}$.

There are many anatomical variations of hypospadias, according to meatal position. There are several classifications, which describe the type of such anomalies such as Barcat $(1973)^{(12)}$, Abramovic $(1981)^{(13)}$, Smith (1938) and Duckett classification.....etc.

Ahmad Alhadedi and Amir Azmy ${ }^{(14)}$ had reviewed such classification as shown and summarized in table(1).

Various techniques were introduced to manage such abnormality, but there is no single method which could be used for all types of hypospadias. If the urethral plate is wide and healthy, it can be tubularized. If it is too narrow to be tubularized, the Snodograss urethrotomy is one option or additional tissue can be laid on the urethral plate using rectangular or pedicled preputial mucosa (Onlay urethroplasty)

Once the urethroplasty is completed the ventral radius of the penis needs to be reconstructed ${ }^{(15)}$. This includes:

a. Meatoplasty creating a silt shaped meatus.

b. Glanuplasty to reconstruct the ventral aspect of the glans.

c. Creating a mucosal collar around the glans.

d. Coverage of the neo-urethra using the lateral pillars of spongiosum.

e. Skin cover with a redistribution of the skin shaft bringing the excess dorsal skin to the ventrum.

f. Circumcision. 


\section{Patients and Methods}

A retrospective study of 125 patients of hypospadias admitted to pediatric surgery centre in Mosul from the period Jan 2005 to Feb were 2007 operated by seven surgeons. All cases were admitted one day before operation for preoperative assessment and preparation.

Surgical technique varied according to the types of anomalies whether distal or proximal hypospadias i.e.; glanular, coronal, distal penile, midshaft, proximal or penoscrotal.

MAGPI and TIP technique are the most common procedures performed. MAGPI was used mainly for glanular, coronal and subcoronal hypospadias, while TIP technique was used for different varieties of hypospadias. Onlay procedure using rectangular or preputial mucosa were done in penoscrotal hypospadias and proximal penile type. Mathiew technique was used only in four patients with distal penile type.

Most of the patients operated by TIP technique were dealt with continuous suturing, while in MAGPI by interrupted suture. In Mathiew and Onlay tube flap continuous suture were also used. In TIP technique, tangential suturing was found better than through and through with less risk of fistula and infection. A catheter is left for a variable period according to the type of procedure.

Tab. (1) Different classification of hypospadias as studied by many authors (Modified from Sheldon and Duckett 1987)

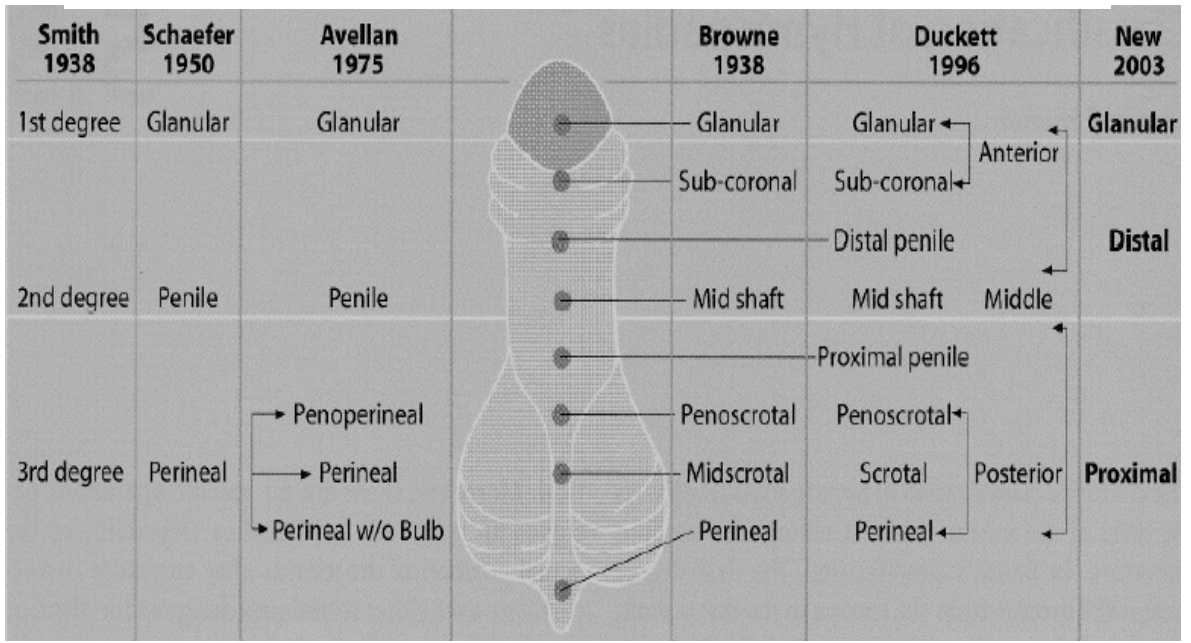

\section{Results:}

1. Our patients' age ranged from 6 months to 12 years. Three patients were below one year, admitted either for dilatation of the opening or circumcision and repair. Table (2) illustrates the age distribution.

Tab. (2) age at presentation

\begin{tabular}{|c|c|c|c|}
\hline GROUP & AGE (years) & Number & Percent \\
\hline \multirow{7}{*}{ Preschool age } & $0.5-1$ & 3 & \multirow{7}{*}{$78.4 \%$} \\
\hline & $1-2$ & 21 & \\
\hline & $2-3$ & 20 & \\
\hline & $3-4$ & 23 & \\
\hline & $4-5$ & 18 & \\
\hline & $5-6$ & 13 & \\
\hline & $6-7$ & 5 & \\
\hline \multirow{5}{*}{ School age } & $7-8$ & 4 & \multirow{5}{*}{$21.6 \%$} \\
\hline & $8-9$ & 3 & \\
\hline & $9-10$ & 2 & \\
\hline & $10-11$ & 6 & \\
\hline & $11-12$ & 7 & \\
\hline
\end{tabular}


Tab (3); type of hypospadias

\begin{tabular}{||l||c||c||}
\hline Type & Number & Percent \\
\hline Glanular & 14 & 11.2 \\
\hline \hline Subcoronal & 48 & 38.4 \\
\hline \hline Distal penile & 37 & 29.6 \\
\hline \hline Mid shaft & 18 & 14.4 \\
\hline \hline Proximal & 7 & 5.6 \\
\hline \hline penoscrotal & 1 & 0.8 \\
\hline Total & 125 & 100 \\
\hline
\end{tabular}

Tab (4); Type of surgical procedure

\begin{tabular}{||l|l||l||}
\hline Procedure & Number & Percent \\
\hline \hline MAGPI & 41 & $33.6 \%$ \\
\hline \hline TIP & 75 & $60 \%$ \\
\hline \hline MATHIEW & 4 & $3.2 \%$ \\
\hline \hline ONLAY TUBE FLAP & 5 & $4 \%$ \\
\hline
\end{tabular}

Tab (5) associated condition

\begin{tabular}{|l|l|l||}
\hline Associated condition & Number of patients & Percent \\
\hline \hline Circumcision & 10 & $8 \%$ \\
\hline \hline Chordee & 8 & $6.4 \%$ \\
\hline \hline Torsion & 5 & $4 \%$ \\
\hline
\end{tabular}

Tab (6) Complications

\begin{tabular}{|c||c||c|}
\hline \hline \multirow{4}{*}{ Minor } & Complication & Number \\
\cline { 2 - 3 } & Infection & 25 \\
\hline \hline \multirow{3}{*}{ Major } & Stricture & 16 \\
\cline { 2 - 3 } & Fistula & 18 \\
\cline { 2 - 3 } & Necrosis and sloughing & 3 \\
\hline
\end{tabular}

2. Type of hypospadias;

We had wide varieties of hypospadias from glanular to penoscrotal as shown in table (3).

3. Types of surgical procedure.

There were 4 main surgical techniques used for repairing hypospadias. The TIP technique was widely used for different types of hypospadias and the MAGPI was used mainly for distal (glanular and subcoronal), while for proximal type the Onlay tube flap was mainly used, table (4).

4. Associated condition: as shown in table (5).
a. Circumcision:
10 patients had circumcision before surgery (six coronal and subcoronal, three distal penile and one penoscrotal).

b. Chordee: 7 patients had mild to moderate chordee. Only one had severe chordee with penoscrotal which had circumcision before repair.

c. Torsion of the shaft of the penis: 4 patients with minor degree and one with severe degree.

5. Complications: there were varieties of complications, illustrated in table 6 .

a. Minor complications such as a mild degree of infection, bleeding or haematoma which occurred after releasing of the tourniquet at the end of the operation were controlled by local measures and antibiotics.

b. Major complication such as stenosis, stricture, fistula formation and skin flap necrosis. 
Hospitalization period varied according to the type of hypospadias and the technique used.

In glanular hypospadias some of them were dealt with as a day case surgery, limited MAGPI procedure performed, and the patients discharged at the same day and all of them had circumcision.

In coronal or subcoronal, usually the procedure is MAGPI or modified MAGPI and the patients discharged after 48 hours (second post operative day) and the catheter is also removed after 48 hours.

In Snodograss (TIP), the patients are usually discharged within 48-72 hours but the catheter is left for 10 days.

In Mathiew: the patients are discharged within 2-3 days but the catheter left for 7 days. Onlay tube flap usually had longer period of hospitalization; it ranges between 5-7 days and the catheter is left for 10 days or more.

\section{Cosmetic appearance:}

In the original MAGPI procedure though the orifice moves forward, but the shape of the glans is somewhat flattened. With some modification of the technique by freeing the meatus and releasing the lateral edge of the urethral opening and doing proper glanuloplasty, this has better shape conical glans than the original MAGPI. The Mathiew procedure shows some edematous thickened ventral skin in the early post-operative period; the meatus is transverse or semicircular in shape. In TIP technique the cosmetic outcome is excellent by having nice conical glans with vertical slit-like meatus.

In our patients all of these procedures were combined with circumcision and trimming of all excess undesired preputial skin with no redundant skin with slit shaped meatus. Mucosal collar is an important addition to improve penile cosmosis.

\section{Post-operative management and complications:}

1. Post-operative bleeding after releasing the tourniquet is controlled by simple pressure and occasionally tight dressing for a short time.

2. Infection: was significant only in four patients, two patients with Mathiew, one in tube flap and one in TIP. The remaining 21 patients had mild degree of infection, which was treated by heavy antibiotic and local treatment.

3. Stenosis or stricture: either at the site of neomeatus as in MAGPI (eight patients) which needed frequent dilatation and seven patients with TIP procedure needed dilatation for 2-3 times, or a stricture occurred at the site of anastomosis as in Onlay tube flap (three patients) and also required dilatation under general anesthesia.

4. Fistula: in MAGPI technique there was no fistula, in TIP technique the were 14 patients, and in Tubular Onlay flap only two patients developed fistula.

5. Flap necrosis; two patients with Mathiew technique developed flap necrosis and ended with recurrence of hypospadias, and one with Onlay tube flap developed very bad infection, flap necrosis and fistula twice.

\section{Discussion:}

The aim of hypospadias repair is to achieve a functionally and cosmetically acceptable urethral opening. More than 150 surgical techniques have been described, using various flaps and grafts to replace or supplement the urethral plate ${ }^{(16)}$.

There is no single method that could be used for all hypospadias as have been stated by Duckett ${ }^{(17)}$, but in this study we have found that TIP technique can be used for a wide range of hypospadias from coronal, subcoronal, shaft and even penoscrotal type. In our pediatric surgical centre we used different procedures for repairing hypospadias.

Distal type hypospadias particularly the glanular form, some of my colleagues may not repair such condition, and may be satisfied with simple circumcision, but we used to do MAGPI to get better shape and parents' satisfaction; 8 patients had MAGPI for glanular hypospadias.

There were 48 patients with coronal and subcoronal types, 33 patients had MAGPI procedure and 15 patients were submitted to TIP technique. The results of MAGPI were fairly good and 8 patients with meatal stenosis required meatal dilatation during follow up in the private or out patient clinics. 
Eight patients out of $33(20 \%)$ developed some flattening of the glans (especially early cases), but those who were subjected to urethral mobilization and glanuloplasty had better cosmetic result \{urethral advance glanuloplasty and prepuplasty\} (URAGP) which is modified MAGPI ${ }^{(18)}$.

In the past 12 years $^{(19-21)}$ some modifications have been made that bring glanular tissue together in a more solid ventral closure that avoids meatal regression. An additional layer approximating the deep glans tissue has been added which replaces the ventral mattress to prevent glans separation that leads to meatal regression. Usually with this modification the glanular reconfiguration produces a nearly normal looking glans with an unnoticeable ventral glans scar. Al khateeb HM had very good cosmetics result with modified MAGPI ${ }^{(22)}$. In fact the cosmetic result is highly acceptable in comparison to original MAGPI.

The main complication which we faced it, is meatal stenosis in eight patients $(20 \%)$, which is well managed by repeated dilatation, none of them required meatetomy.

Others have reported their result with MAGPI; Livne et al $^{(23)}$, had excellent result in 66 patients with no meatal stenosis or retraction, and only three cases having minor cosmetic deficiencies. Mac Millan et al (24) studied 44 MAGPI results, all except one patient had excellent cosmetic result. Ozen and Whitaker ${ }^{(25)}$ had a $6 \%$ rate of meatal retraction in 67 cases and $91 \%$ had excellent result. Issa and Gearhart described eight cases with meatal retraction, five patients attributed to technical failure and three due to poor case selection. Inappropriate application of MAGPI technique to unsuitable cases are mostly the cause of the poor result reported by others ${ }^{(26,)}$.

TIP Technique was performed in 75 patients (60\%), 5 patients with coronal, 15 patients with subcoronal, 35 patients with distal penile, 16 midshaft, 3 patients with proximal and 1 patient penoscrotal. This technique provides the narrow urethral plate to become enough for easy tubularization and provides a vertically oriented and cosmetically normal neo-urethra.
Seven patients were managed by 2 layer closure ( The neo-urethra and skin) while the majority 68 patients $90 \%$ were managed by 3 layer closure which include neourethra, dorsal vascular flap and skin.

In our early practice with TIP technique, patients with 2 layer closure had fistula in 3 out of 7 patients while the remaining 68 patients with 3 layer closure had fistula in 11 patients, most of them had narrow urethra. The incidence of fistula was $42.8 \%$ in two layer closure, while it was around $16 \%$ in 3 layer closure.

Another factor which minimizes the fistula is to have wide meatus with meticulous closure of the epithelium rather than leaving raw area near the neo meatus (personal observation).

This practical point was also observed by Anwar-ul-Hag ${ }^{(27)}$ who advised special precaution for maturing the meatus. Post operative calibration or dilatation to prevent such complication is helpful to minimize fistula. Snodograss and Loranzo ${ }^{(28)}$ reported, that 33 patients with proximal type of hypospadias operated on by TIP technique, 7 cases $(21 \%)$ developed fistula. While Anwar-ul-Hag et $\mathrm{al}^{(27)}$ operated on 30 patients who had anterior or distal hypospadias by TIP technique, 3 cases $(10 \%)$ developed fistula and one complete break- down which is nearly similar to our result with 3 layer closure. Nahas ${ }^{(29)}$ operated on 33 patients, most of them distal type hypospadias with 3 patients $(9 \%)$ only developed fistula. Chenge ${ }^{(30)}$ reported that fistula can be avoided by interposition of vascular dartus flap between the neo urethra and skin and they reported a fistula rate as low as $1 \%$. This may be the result of greater experience and good selection of cases.

In general we have excellent cosmetic result with near normal glans configuration, and slit like meatus, which is superior to (MAGPI) which may give bifid glans and rounded opening and if we compare it to Mathiew, is transverse slit with sometimes bulky inferior skin.

This cosmetic result goes with the result of another report. Selami ${ }^{(31)}$ who confirmed that no other procedure can create a vertical 
oriented meatus and near normal configuration of the glans, except TIP technique.

Tokuc and et $\mathrm{al}^{(32)}$ also reported excellent cosmetic results with vertical slit like meatus at the tip of the glans which were obtained in all patients even in those who had post-operative urethral fistula. They had post-operative complications in 25 out of $210(12 \%)$, meatal stenosis in 5 , and urethral fistula in 7 patients while 13 developed fistula and stenosis; all of the complicated cases required another surgical intervention and repaired successfully on the next procedure.

Mathiew procedure was done in 4 patients, 2 of them had necrosis and sloughing of the lower flap with recurrence of the hypospadias that was due to false selection and lack of good experience of the technique. Now; there is modified Mathiew which includes a deep incision of urethral plate started close to the tip of the glans and including the dorsal part of the hypospadic meatus ${ }^{(33)}$. We haven't performed this modified technique to any one of our patients. We found that all cases which fit the Mathiew technique can be operated by TIP technique and for this reason we stopped using Mathiew and replacing it by TIP.

The Onlay Tube Flap was done for more proximal penile hypospadias, most of them were older children (9-12 years) and having big phallus; 5 patients were operated with this technique. One of them developed postoperative stricture which necessitated repeated dilatation under GA and the other 2 developed fistula, which required another session for the repair of fistula. One of the two recurrent cases developed another fistula and treated by another operation. We have only two patients who had a good result from the first operation.

In pediatric surgery, we tried to avoid operating on complicated proximal hypospadias cases. There were some penoscrotal cases or scrotal hypospadias with bifid scrotum and those with ambiguous genitalia, were referred to another centre. So we can not compare our results regarding proximal type of hypospadias with others because of our limited experience and small sample.

\section{Associated condition}

The presence of circumcision prior to hypospadias repair in our experience was found to be not a big obstacle in completing the repair, but it could be a major problem with more proximal types which need Onlay flap or tube flap.

Ten patients were with circumcision, nine of them were with distal hypospadias, and they were easily repaired with out difficulties by MAGPI or TIP technique, and one with proximal (penoscrotal) type of hypospadias was also successfully managed without difficulties by TIP technique.

Eight patients with chordee were improved and corrected with degloving of the penile skin and only one case needed dorsal plication, with acceptable cosmetic result.

Five patients with torsion of the shaft of the penis got some improvement of the torsion after repair and circumcision.

\section{Conclusion:}

TIP technique was used for the first time in our centre during 2005-2006, and found to be simple applicable to a wide range of hypospadiac anomalies with excellent cosmetic result and can replace other well known procedures like MAGPI or Mathiew.

MAGPI is still to be used for more distal hypospadias cases with some modification to get more acceptable cosmetic result.

Presence of circumcision prior to the repair with distal hypospadias is found to be not a big problem and the repair can be performed without much difficulty with MAGPI or TIP technique.

\section{Acknowledgement}

I would like to thank all my colleagues and students in AL-khansa'a pediatric surgery center who agreed to include their cases in this study and helped me in reviewing the case records and typing this article.

\section{References:}

1. Braka, A. A: Long-term view of hypospadias. Br. J Plast. Surg., 42: 251, 1989.

2. Ahmed SF, Cheng A, Hughes $1 A$. Assessment of gonadotrophin gonadal axis in Androgen insensitivity syndrome. Arch Dis child 1999; 80: 324-9. 
3. Boehmer ALM, Nijman RJ, Lammers BA et al. Etiological studies of severe or familial hypospadias. J Urol 2001; 165: 1246-54.

4. Feyaerts A. Forest MG, Morel $\mathrm{Y}$ et al. Endocrine screening in 32 consecutive patients with hypospadias. J Urol 2002; 168: $720-5$.

5. Stoll, C, Alembik Y, Roth MP, Dott B, Genetic and envirmental factors in hypospadias. J Med. Genet 1990; 27: 55963.

6. Gatti JM, Kirsch AJ, Troyer WA, PerezBray field MR Smith EA, Scherz HC. Increased incidence of hypospadias in small-for-gestational age infants in a neonatal intensive care unit. BJU int 2001; 87: 548-50.

7. Fredell L, Kochum 1, Hansson $E$ et al. Heredity of hypospadias and the significance of low birth weight. J Urol 2002; 167: 1423-7.

8. Paulozzi LJ. International trends in rates of hypospadias and cryptochidism. Envir Health perspect 1999; 107: 297-302.

9. Sultan C, Balaguer P, Terouanne B et al. Envermental xenooestrogens, antiandrogens and disorders of male sexual differentiation. Mol Cell Endocrinol 2001; 178: 99-105.

10.Dunphy JE, Way LW. Current Surg. diagnosis and treatment 3rd Ed. 1977 Lange $P$ 862-66.

11.O'Neill JA, Grosfeld J.L., Fonkalsiud EW, Coron AG and Caldamone AA. Principles of Pediatric Surgery $2^{\text {nd }}$ Ed Mosby 2003; Chapt 77 p 761-70.

12. Barcat J: Current Concepts of Treatment in Horton C. E. ed: Plastic and Reconstructive Surgery of the Genital Area.Boston, little brown 1973 p 249-263

13.Abramovic V. Operative treatment of severe forms of hypospadias. Urol Clin North Am; 8(3): 431, 1981.

14. Hadidi AT. Y - V. glanuloplasty a new modification in the surgery of hypospadias. Kasr Aini Med J. Vol 2 No 2 Dec 1996.

15.Mouriquand P.D.E Mure P.Y, Crrent concepts in hypospadiology ESU organized course (update in urology)Aleppo, Syria 11 Sept 2004.
16.Clup OS, McRoberts JW, Hypospadias; in Alken CE, Editors. Encyclopedia of Urology. New York Springer. V. 1968; 11307-11344.

17.Duckett JW. Hypospadias repair in: O'Donnel and Koff SA, Editors Pediatric Urology 3rd ed. Oxford: Butter worth, Heinemann 1997: 551-568.

18. Keramidas DC and Soutis ME. Urethral advancement glanduloplasty and prepucioplasty (URAGP).Journal of internal workshop on hypospadias, 2002, Istanbul, Turkey.P23

19.Duckett JW. Hypospadias. In Walsh PC, Gittes RF, perlmutter AD, Stamey TA. Campbell's Urology 5th Ed. Philadelphia: WB Saunders, 1986 pp 1969-1999

20.Gibbons MD, Gonzales ET Jr. the subcoronal meatus. J Urol 1983; 130: 739.

21.Duckett JW. Hypospadias in Gillen water JY Gray hack JT, Howards SS Duckett JW (eds). Adult and pediatric Urology 2nd Edition Chicago: Mosby year book, 1991: pp 2103-2140.

22.Al-Khateeb HM. Meatal advancement glanduloplasty (MAGPI) for coronal Hypospadias with Modification IPMJ Vol. 3 No 4, 2004.

23.Livne PM, Gibbons MD, Gonzales Excellent, Meatal advancement and glanuloplasty: an operation for distal hypospadias. J Urol 1984; 131: 95.

24.McMillan RDH, Churchill BM, Gilmore RF. Assessment of urinary stream after repair of anterior hypospadias by meatoplasty and glanuloplasty. J Urol 1985; 134: 100102.

25. Ozen HA, Whitakar RJ. Scope and limitation of the MAGPI hypospadias repair Br. J. Urol 1987; 59:81.

26. Issa MM, Gearhart JP. The failed MAGPI; management and prevention. $\mathrm{Br} \mathrm{J}$ Urol 1989; 64: 620- 622.

27.Anwar -ul- Hag, Bader, I, Akhter N, and Abbasi Z. tabularized incised plate urethroplasty of hypospadias JCPSP Aug 2004 Vol 1 No 2.

28.Snodgrass WT and Lorenzo. Tubularised incised-plate urethroplasty for proximal 
Hypospadias BJU International (2002) 89, 90-93.

29.Nahas BW. Snodograss repair for virgin cases of distal hypospdias experience study from Damascus Syria JABMS 2004; 6(3): 275-78.

30.Cheng EY. Steenivas N, Vemulapalli et al. Snodgrass hypospadias repair with vascularized dartos flap. The perfect repair for virgin cases of hypospadias $\mathrm{J}$ Urol 2002; 168: 1723-1726.

31.Selami S, Snodograss W .A New algorathem for primary hypospadias repair based on TIP urethroplasty. J.Ped Surg 2003; 38: 1157-61
32.Tokuc,R,Basok E K, Memis O.F. Peltekoglu E. Unlusoy z, Snodgrass procedure in the treatment of the distal and mid penile hypospadias: What we have learned from 7 year experience on 210 patients (abstract). Journal of international work shop on hypospadias 2002 Istanbul Turkey.P11

33.Franchella .A. Casadio G, Pavanella P. Modified Mathiew procedure for hypospadias repair based on a midline urethral plate incision: Evaluation with Uroflowmetry follow up studies (abstract). Journal of international work shop on hypospadias 2002 Istanbul Turkey.P77. 